\title{
Capecitabine from X-ray powder synchrotron data. Corrigendum
}

\author{
Jan Rohlicek, ${ }^{\mathrm{a} *}$ Michal Husak, ${ }^{\mathrm{a}}$ Ales Gavenda, ${ }^{\mathrm{b}}$ Alexandr Jegorov, ${ }^{\mathrm{c}}$ Bohumil \\ Kratochvil ${ }^{\mathrm{a}}$ and Andy Fitch ${ }^{\mathrm{d}}$
}
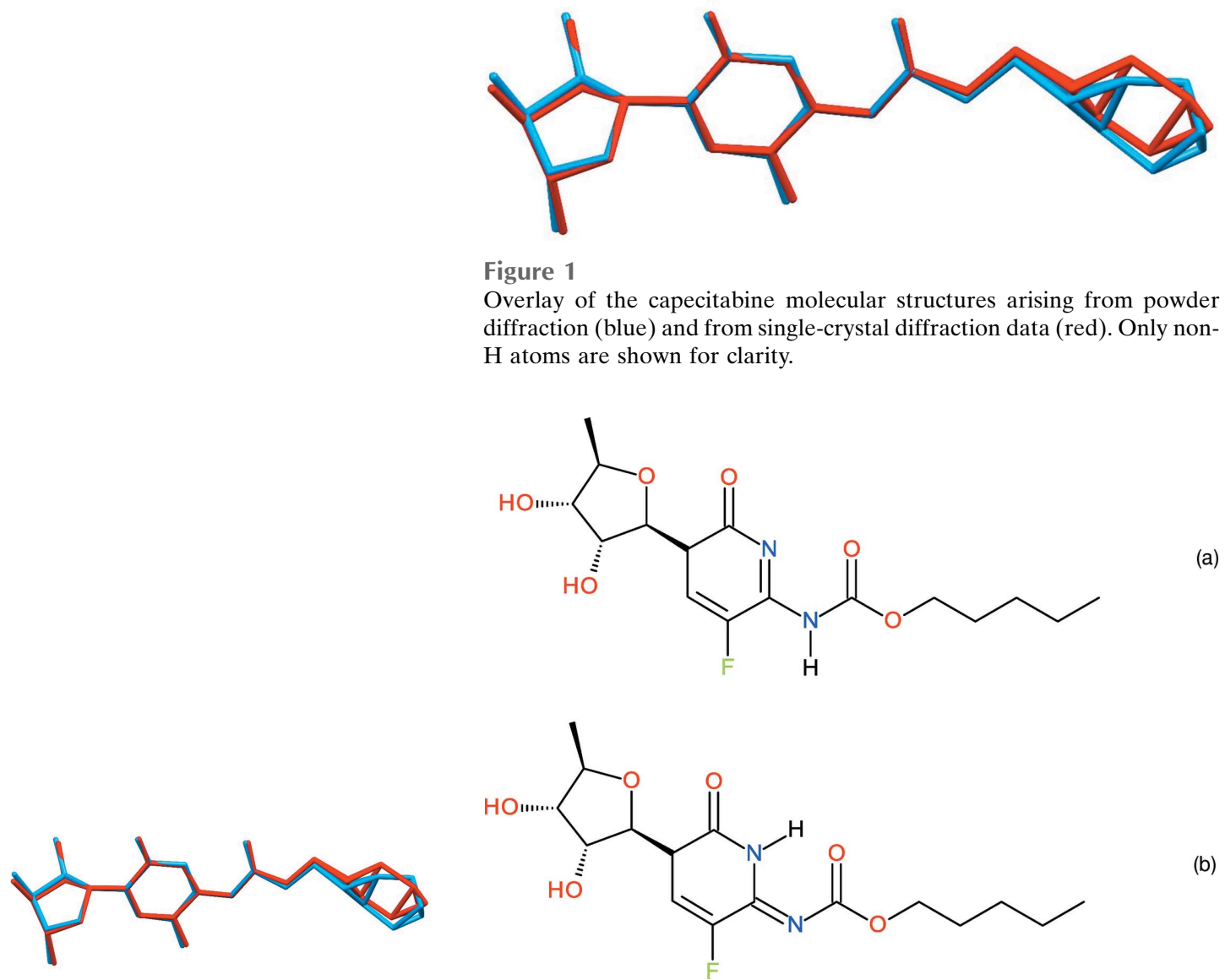

Figure 1

Overlay of the capecitabine molecular structures arising from powder diffraction (blue) and from single-crystal diffraction data (red). Only non$\mathrm{H}$ atoms are shown for clarity.<smiles>CCCCCOC(=O)NC1=NC(=O)C([C@@H]2OC(C)[C@@H](O)[C@H]2O)C=C1F</smiles><smiles>CCCCCOC(=O)/N=C1\NC(=O)C(C2OC(C)[C@@H](O)[C@H]2O)C=C1F</smiles>

(b)

Figure 2

Schemes for the tautomeric forms of capecitabine $(a)$ assumed in the powder-diffraction study and $(b)$ established in the single-crystal study of Malinska et al. (2014). 
the disordered part of the molecule (Fig. 1). Since singlecrystal diffraction is more sensitive to $\mathrm{H}$ atoms than powder diffraction, Malinska et al. (2014) were able to locate the $\mathrm{H}$ atoms directly. This indicated a different tautomeric form of capecitabine to that assumed in our study, and as they pointed out, we had therefore placed one $\mathrm{H}$ atom wrongly.

In our defence, in the powder study, we placed the $\mathrm{H}$ atoms geometrically according to a reasonable chemical structure for capecitabine, which shows the tautomeric $\mathrm{H}$ atom attached to the $\mathrm{N}$ atom of the carbamate group and the plausible formation of an intermolecular $\mathrm{N}-\mathrm{H} \cdots \mathrm{O}$ hydrogen bond. As shown by Malińska et al. (2014), the $\mathrm{H}$ atom is actually located on the $\mathrm{N}$ atom of the pyrimidine ring (Fig. 2), thereby forming an intramolecular $\mathrm{N}-\mathrm{H}$... O link.
With respect to the fact that structure solution from powder diffraction data is based on the proposed molecular structure, readers should beware of the incorrectly placed $\mathrm{H}$ atom in Rohlicek et al. (2009) and they should be also beware of the wrong enantiomer in a single-crystal study of Malińska et al. (2014).

\section{References}

Kratochvil, B., Husak, M., Korotkova, E. I. \& Jegorov, A. (2016). Chem. Listy, 110, 40-47.

Malińska, M., Krzecyński, P., Czerniec-Michalik, E., Trzcińska, K., Cmoch, P., Kutner, A. \& Woźniak, K. (2014). J. Pharm. Sci. 103, 587-593.

Rohlicek, J., Husak, M., Gavenda, A., Jegorov, A., Kratochvil, B. \& Fitch, A. (2009). Acta Cryst. E65, o1325-01326. 